Research Article

\title{
Formulation and Evaluation of Sintered Gastroretentive Tablets of Pioglitazone
}

\author{
Dr.K.V. Ratnamala*, E.Veena Rani \\ Department of Pharmaceutics, RBVRR Women's College of Pharmacy, Barkatpura, Hyderabad, Telangana, India. \\ *Corresponding author's E-mail: ratnakolapalli123@gmail.com
}

Received: 20-04-2021; Revised: 25-06-2021; Accepted: 04-07-2021; Published on: 15-07-2021. \begin{abstract}
The aim of the present study is to prepare sintered gastroretentive tablets of Pioglitazone and to study the effect of sintering on invitro dissolution study, hardness and friability. Sintering is defined as the process of compaction or formation of compact at a temperature below the melting point of solid constituent for the purpose of increasing its strength by bonding the particles together. EVA 1802, stearic acid, carnauba wax, and natural polymers like almond gum, xanthun gum, guar gum were used. The tablets were prepared by direct compression and wet granulation technique using PVP as binder and EVA, carnauba wax, stearic acid in different concentration of $10 \%, 15 \%$ were used in preparation. The prepared tablets were subjected to sintering at three different temperatures of $50,60,70^{\circ} \mathrm{C}$ for three different time periods of $1 \mathrm{hr}, 2 \mathrm{hr}, 3 \mathrm{hrs}$ in hot air oven. Precompression and post compression parameters were performed. Results showed that the release rate of the drug was inversely related to the sintering temperature and time of sintering. The optimum drug retardation occurred in the tablets at $70^{\circ} \mathrm{C}$ for $3 \mathrm{hrs}$. increasing the temperature and time of exposure to a particular temperature often decreases the release rate of the drug. In addition, the hardness of the sintered tablets was increased with increasing sintering temperature and duration of sintering whereas friability of tablets was found to be decreased with increasing time. The optimized formulations $\mathrm{F} 3(\mathrm{SA}+\mathrm{CW}+\mathrm{XG}), \mathrm{F} 4(\mathrm{SA}+\mathrm{CW}+\mathrm{EVA})$ sintered at $70^{\circ} \mathrm{C}$ for $3 \mathrm{hrs}$ showed the maximum release of $70-80 \%$. from the kinetic profile it shows that the drug release followed zero order and nonfickian diffusion mechanism. Thus, the formulations F3 and F4 was considered to be the best formulations among all the 6 formulations sintered at various temperature and various time periods. Hence it shows the suitability of EVA,SA,CW, natural polymers for preparing the sintered gastroretentive tablets of Pioglitazone.
\end{abstract}

Keywords: thermal sintering technique, Pioglitazone, natural polymers and EVA.

QUICK RESPONSE CODE $\rightarrow$

DOI:

10.47583/ijpsrr.2021.v69i01.007

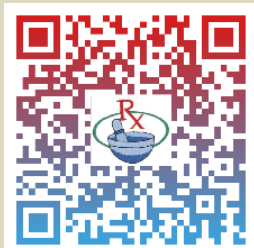

DOI link: http://dx.doi.org/10.47583/ijpsrr.2021.v69i01.007

\section{INTRODUCTION}

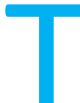

ablets are defined as the solid unit dosage form of medicament, with or without suitable excipients and prepared by molding or by compression. The excipients can include diluents, binders or disintegrating agents, glidants and lubricants to ensure efficient tablet, disintegrating agent to promote tablet break up in the digestive system, flavoring agent are added to enhance the taste, pigmentation to make tablet visually attractive. A polymer coating is often applied to make tablet smoother and easier to swallow, to control the release rate of the active ingredient, to make it more resistant to the environment, or to enhance the tablets appearance ${ }^{1}$. Certain drugs are absorbed from the gastrointestinal tract and will be eliminated quickly because of short half-life as a result frequent administration is required to attain suitable therapeutic activity ${ }^{2}$. The dosage form that could be retained in the stomach for extended period of time promoting slow release of the drug called as
"Gastroretentive drug delivery system". Prolonged gastric retention improves bioavailability, increases the duration of drug release, reduces the drug wastage, and improves the solubility of the drugs that are less soluble in high $\mathrm{pH}$ environment ${ }^{3}$.

Gastric retention can be achieved by various techniques like:

- High density system ${ }^{4}$ - dosage form that could be retained in the stomach by sinking to the bottom.

- Low density system ${ }^{5}$ - dosage form that float over the gastric fluid.

- Mucoadhesive system ${ }^{6}$-dosage form that causes bioadhesion to the stomach mucosal.

- Unfoldable, extendible or swelling systems ${ }^{7}$-system that prevents the emptying of dosage form through pyloric sphincter of stomach.

- Superporous hydrogel system and magnetic system ${ }^{8}$.

\section{Sintering technique}

Sintering can be defined as the bonding of adjacent particle surfaces in a mass of powder. The sintering procedure had been used for the fabrication of sustained release matrix tablets and the stabilization of drug 
permeability of film coating that derived from various pharmaceutical lattices ${ }^{9}$. Sintering concept is a recently introduced technique in the pharmaceutical sciences. Sintering generally occurs at elevated temperature and involves mainly three steps -

Joining of the adjacent particles together termed as neck growth, formation of interconnecting pore channels termed as densification followed by formation of spherical shape of particles which tends to flow into the pores within it due to the difference between vapor pressure and cross-sectional area of the pores neck.

Thermal sintering involves heating of a compact at a temperature below the melting points of the solid constituents in a controlled process. The sintering method involves the exposure of the dosage form to temperature which softens the polymer matrix matrix and leads to the formation of welded bonds. The drug present present in tablets will get entrapped in the matrix formed, that results in controlled release of the active ingredient.

However, the method can be applied to those drugs that are temperature resistant on exposure that is the limiting factor for many drugs that degrade at high temperatures.

Stages of sintering are mentioned below ${ }^{10,11}$ Interparticle bonding, Neck growth, and pore closure

Pioglitazone is a thiazolidinedione antidiabetic agent that depends on the presence of insulin for it's mechanism of action. It decreases insulin resistance in the periphery and in the liver resulting in increased insulin -dependent glucose disposal and decreases hepatic glucose output. Pioglitazone is a potent agonist for peroxisome proliferator-activated receptor gamma (PPAR-gamma). Activation of PPAR-gamma nuclear receptors modulates the transcription of number of insulin responsive genes involved in the control of glucose and lipid metabolism.
The goal of the study is to develop Sintered Gastroretentive tablets of Pioglitazone inorder to promote the slow release of the drug for more than $12 \mathrm{hrs}$.

\section{MATERIALS AND METHODODLOGY}

\section{Materials}

Pioglitazone was obtained as a gift sample from MSN organic Pvt.Itd. All other chemicals were obtained from S.D. Fine chemicals. All chemicals were of analytical grades as required.

\section{Methodology}

\section{Direct compression}

Direct compression is the process by which tablets are compressed from powder mixture of API and suitable excipients and compression was done by automatic punching machine using $6 \mathrm{~mm}$ punch. Prepared tablets were kept in the hot air oven at three different temperatures of $50,60,70$ ㅇ $\mathrm{C}$ for three different time period of $1,2,3 \mathrm{hr}$.

\section{Wet granulation}

Tablets were prepared by mixing dry primary powder particles using a granulating fluid. Granulation was achieved by slowly adding the binder solution to the dry mixture, after reaching the desired consistency, it is subjected to screening. The granules were dried in the oven at $45^{\circ} \mathrm{C}$ and then removed and sieved again. To this mixture lubricant and glidant was added and the granules were subjected to punching under $6 \mathrm{~mm}$ punch. Prepared tablets were subjected to sintering at different temperatures of $50,60,70^{\circ} \mathrm{C}$ for different time periods of $1,2,3 \mathrm{hrs}$ respectively.

\section{Solubility Studies of Pioglitazone}

Solubility studies were carried out in Methanol, Water, Dimethyl sulphoxide, and Buffers like 1.2, 2.2, 3.4, 4.1, 5.6, $6.8,7.4$

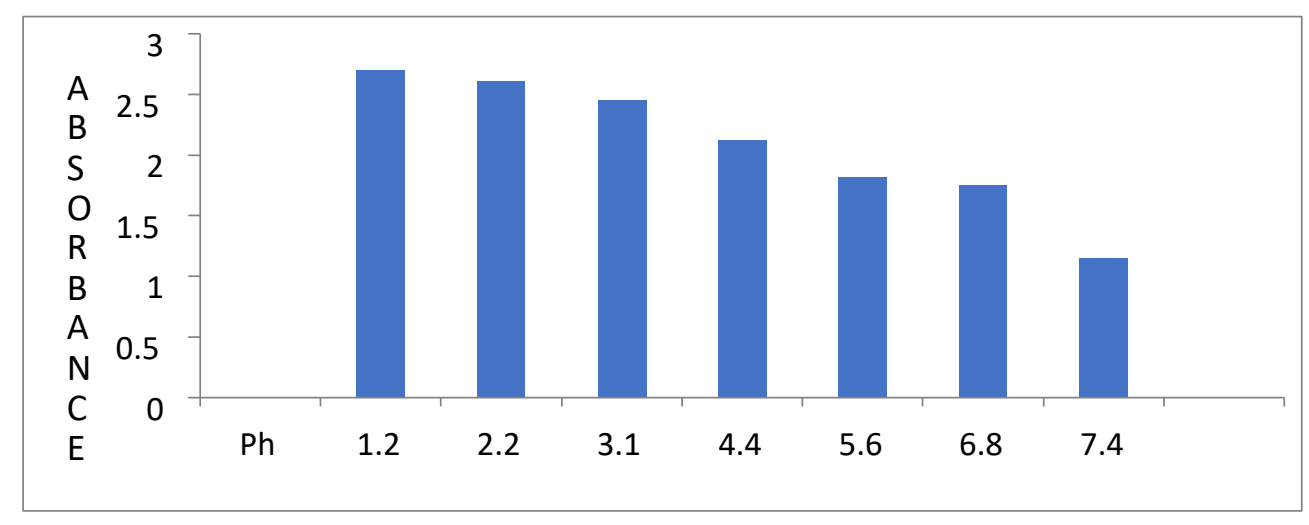

Figure 3.1: Solubility analysis- comparative study of Pioglitazone solubility

Pioglitazone showed greater solubility in the $1.2 \mathrm{pH}$ buffer and least solubility in the $7.4 \mathrm{pH}$ buffer it confirms that it has good absorption from the stomach environment

\section{Evaluation Tests}

Evaluation was performed to access the physicochemical properties and release characteristics of the developed formulations. 


\section{Physical Evaluation}

The formulated tablets were evaluated for physical characteristics like appearance, size and shape, organoleptic properties, thickness, Hardness, Friability, weight variation and drug content.

\section{Hardness}

The prepared tablets were selected randomly to determine the hardness uniformity studies, which was determined by using Pfizer hardness tester. It was expressed in $\mathrm{kg} / \mathrm{cm} 2$.

\section{Friability}

The friability of tablets was determined by using Roche friabilator. It is expressed in percentage. 20 tablets were selected randomly and were weighed initially and transferred into friability test apparatus. The friabilator was operated at $25 \mathrm{rpm}$ for $4 \mathrm{~min}$ and the tablets were weighed again.

The \%friability was calculated as:

$\mathrm{F}=\mathrm{W}$ (initial) $-\mathrm{W}($ final $) / \mathrm{W}($ initial $) \times 100$

Where, F- friability of tablets, W(initial)- initial weight of tablets, W(final)- final weight of tablets

\section{Drug content}

Tablets were weighed and powdered in mortar and pestle. $10 \mathrm{mg}$ of the tablet powder was taken into $10 \mathrm{ml}$ volumetric flask and volume was made up to the mark by using methanol. It was subjected to sonication for few minutes until the powder dissolves completely from the above solution $1 \mathrm{ml}$ was transferred into $10 \mathrm{ml}$ volumetric flask and volume was made up to mark of $10 \mathrm{ml}$ with $0.1 \mathrm{~N}$ $\mathrm{HCl}$ buffer.

Further dilutions were made and the absorbance of the solutions was measured at $269 \mathrm{~nm}$ using UVspectrophotometer.

\section{Formulation Table}

\section{Floating Evaluation}

The formulated tablets were evaluated for Floating lag time, invitro buoyancy studies and total floating time.

\section{Floating lag Time and Total floating time}

The floating lag time can be defined as the time taken by the tablet to emerge on the surface of the dissolution medium, and the time the tablet constantly float on the surface of the medium is known as Total floating time.

The invitro buoyancy was determined by floating lag time. The tablets were placed in a $250 \mathrm{ml}$ beaker, containing $200 \mathrm{ml}$ of $0.1 \mathrm{~N} \mathrm{HCl}$. The time required for the tablet to rise to the surface and float was determined as Floating lag time and the time period up-to which the tablet remain buoyant determined as Total floating time.

\section{Swelling index}

The floating tablets were weighed individually (Wo) and placed separately in a beaker containing $200 \mathrm{ml}$ of $0.1 \mathrm{~N}$ $\mathrm{HCl}$ and incubated at $37 \pm 1^{\circ} \mathrm{C}$. At regular interval of $1 \mathrm{hr}$ until 24hrs, the floating tablets were removed from beaker and excess surface liquid was removed carefully using the tissue paper. The swollen floating tablets were then reweighed $(\mathrm{Wt})$ and \%swelling index was calculated as Swelling index $(\%)=\mathrm{Wt}-\mathrm{Wo} / \mathrm{Wo} \times 100$

\section{Invitro dissolution studies}

The invitro dissolution study was performed by using USP type II paddle apparatus at speed of 100rpm. Exactly $900 \mathrm{ml}$ of $0.1 \mathrm{~N} \mathrm{HCl}$ was used as the dissolution medium and the temperature was maintained at $37 \pm 0.5^{\circ} \mathrm{C}$. A sample of $10 \mathrm{ml}$ solution was withdrawn from the dissolution apparatus at a specified time interval for $24 \mathrm{hrs}$ and the same volume was replaced with fresh buffer. Absorbance of these solutions was measured at $269 \mathrm{~nm}$ using U. V spectrophotometer.

\begin{tabular}{|c|c|c|c|c|c|c|}
\hline Ingredients & F1(mg) & F2(mg) & F3(mg) & F4(mg) & F5(mg) & F6(mg) \\
\hline Pioglitazone & 15 & 15 & 15 & 15 & 15 & 15 \\
\hline Stearic acid & 18 & 18 & 18 & 18 & 18 & - \\
\hline Carnauba wax & 18 & 18 & 18 & 18 & - & 18 \\
\hline Guar gum & 18 & - & - & - & - \\
\hline Almond gum & - & 18 & - & - & - \\
\hline Xanthun gum & - & - & 18 & - & - & - \\
\hline EVA & - & - & - & 12 & 12 & - \\
\hline PVP & 6 & 6 & 6 & - & - \\
\hline MCC & 12 & 12 & 12 & 15 & 15 & 15 \\
\hline Magnesium stearate & 2.4 & 2.4 & 2.4 & 6 & 6 & 6 \\
\hline Talc & 2.4 & 2.4 & 2.4 & 2.4 & 6 & 6 \\
\hline Lactose & 24 & 24 & 24 & 29.4 & 43.8 & 43.8 \\
\hline Sodium carbonate & 4.2 & 4.2 & 4.2 & 4.2 & 4.2 & 4.2 \\
\hline Total weight & 120 & 120 & 120 & 120 & 120 & 120 \\
\hline
\end{tabular}




\section{RESULTS AND DISCUSSION}

Cumulative \% Drug Release Profile of F3 and F4 at $70^{\circ} \mathrm{C}$

\begin{tabular}{|c|c|c|c|c|c|c|}
\hline \multirow[t]{2}{*}{ Time (hrs) } & \multicolumn{3}{|c|}{$70^{\circ} \mathrm{C}(\mathrm{F} 3)$} & \multicolumn{3}{|c|}{$70^{\circ} \mathrm{C}(\mathrm{F} 4)$} \\
\hline & $1 \mathrm{hr}$ & $2 \mathrm{hr}$ & $3 \mathrm{hr}$ & $1 \mathrm{hr}$ & $2 \mathrm{hr}$ & $3 \mathrm{hr}$ \\
\hline 1 & $15.7 \pm 2.2$ & $14.9 \pm 0.8$ & $12.8 \pm 0.5$ & $15.4 \pm 0.3$ & $14.1 \pm 0.7$ & $12.4 \pm 0.6$ \\
\hline 2 & $20.8 \pm 0.2$ & $19.9 \pm 0.7$ & $18.9 \pm 0.8$ & $24.4 \pm 0.1$ & $23.4 \pm 0.8$ & $20.5 \pm 0.8$ \\
\hline 3 & $33.6 \pm 0.7$ & $32.0 \pm 0.8$ & $30.1 \pm 0.8$ & $36.2 \pm 0.4$ & $32.5 \pm 0.4$ & $30.3 \pm 0.4$ \\
\hline 4 & $37.8 \pm 0.7$ & $37.8 \pm 0.6$ & $36.4 \pm 0.8$ & $48.3 \pm 0.4$ & $47.2 \pm 0.2$ & $45.2 \pm 0.4$ \\
\hline 5 & $45.1 \pm 0.6$ & $42.7 \pm 0.3$ & $40.4 \pm 0.9$ & $56.3 \pm 0.7$ & $54.2 \pm 0.8$ & $52.4 \pm 0.4$ \\
\hline 6 & $47.5 \pm 0.7$ & $47.5 \pm 0.7$ & $46.1 \pm 0.2$ & $60.6 \pm 0.7$ & $59.1 \pm 0.3$ & $59.1 \pm 0.5$ \\
\hline 7 & $55.2 \pm 0.8$ & $54.1 \pm 0.4$ & 53.50 .1 & $66.4 \pm 0.7$ & $65.7 \pm 0.7$ & $64.3 \pm 0.8$ \\
\hline 8 & $64.6 \pm 0.7$ & $63.5 \pm 0.3$ & 59.40 .4 & $72.2 \pm 0.7$ & $70.2 \pm 0.4$ & $69.7 \pm 0.6$ \\
\hline 9 & $74.2 \pm 0.4$ & $70.5 \pm 0.6$ & $66.4 \pm 0.5$ & $77.3 \pm 0.4$ & $75.3 \pm 0.1$ & $74.2 \pm 0.4$ \\
\hline 10 & $82.7 \pm 0.6$ & $80.5 \pm 0.8$ & $71.2 \pm 0.4$ & $84.3 \pm 0.4$ & $83.2 \pm 0.4$ & $79.3 \pm 0.7$ \\
\hline
\end{tabular}

\section{Kinetic Profile of the Optimized Formulations (F3)}

\section{Zero order plot}

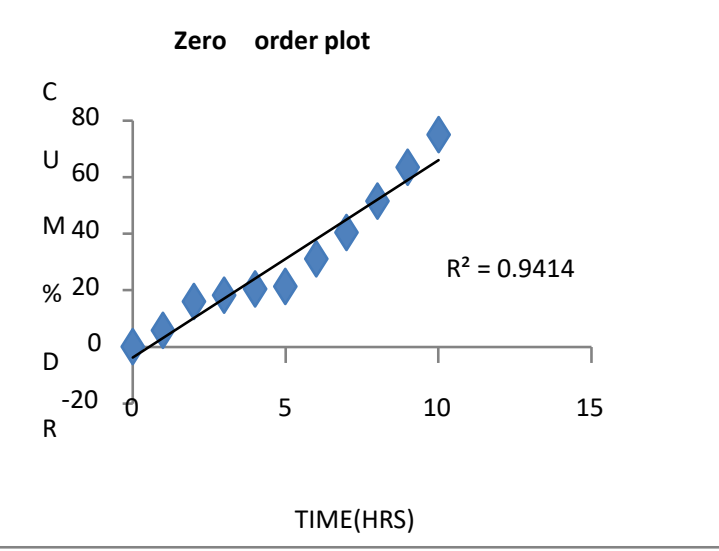

\section{First order plot}

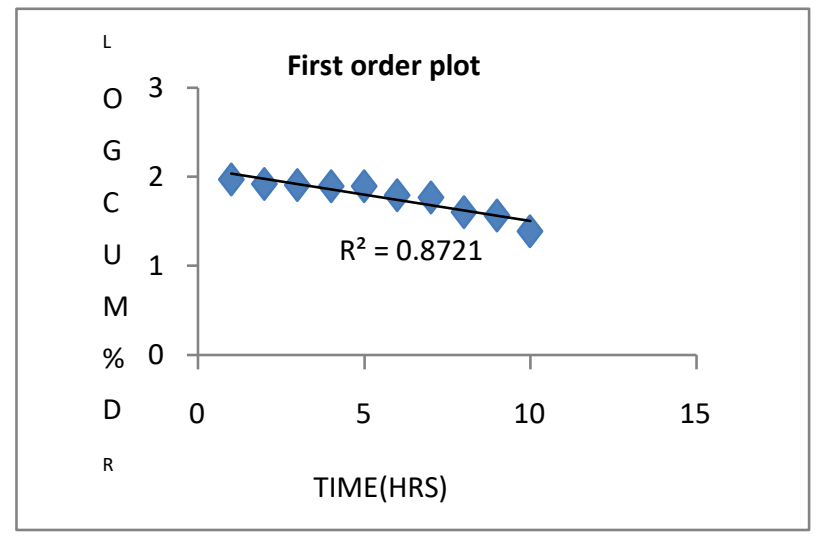

\section{Higuchi plot}

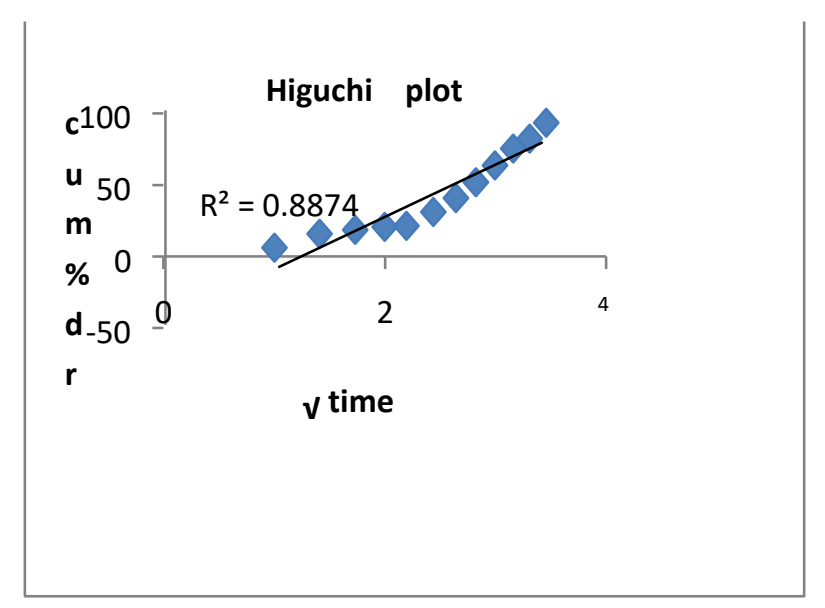

\section{Peppas plot}

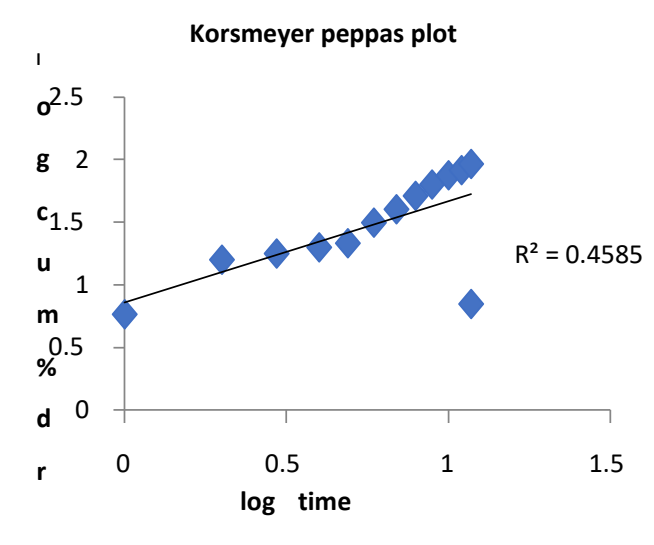

Figure 5.2: Zero order, First order, Higuchi and Peppas plot for F3 Formulation. 


\section{Kinetic Profile of Optimized Formulation(F4)}

\section{Zero order plot}

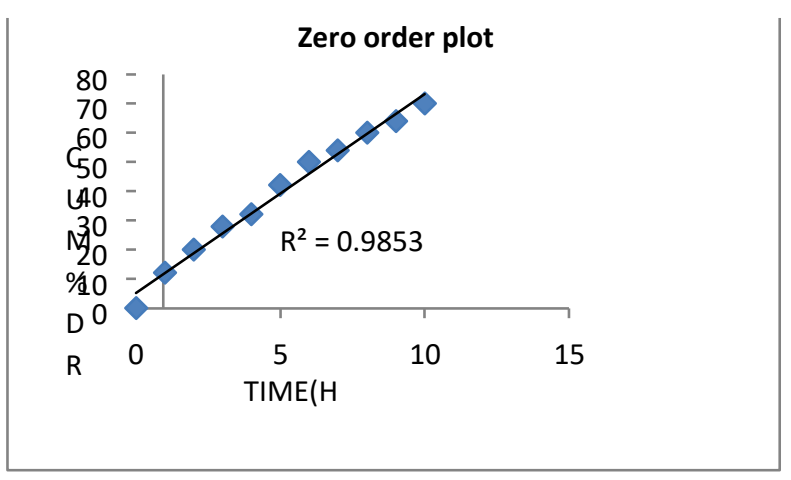

\section{First order plot}

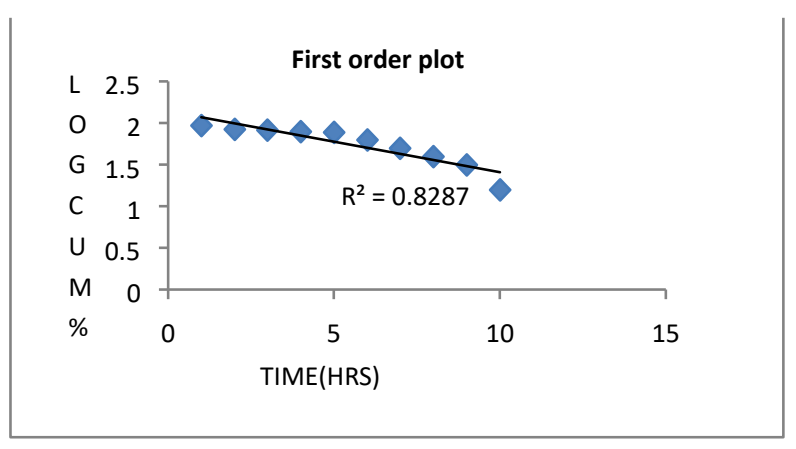

\section{Higuchi plot}

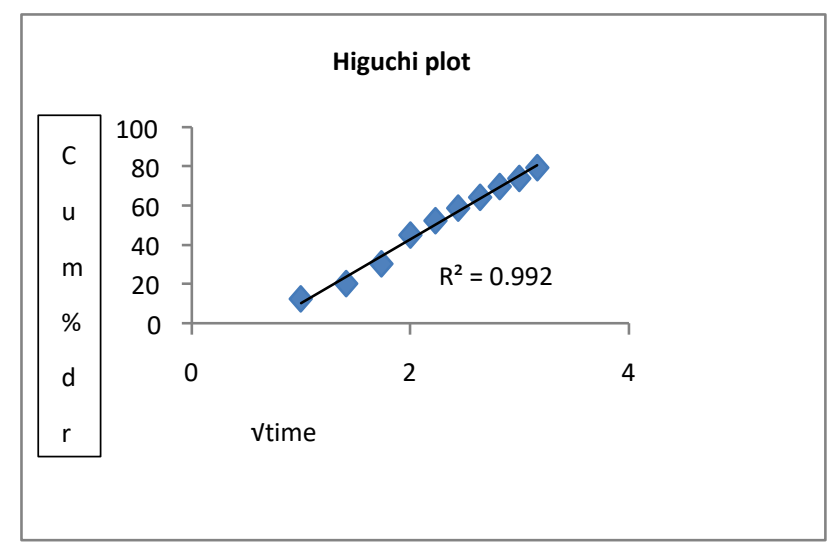

\section{Peppas plot}

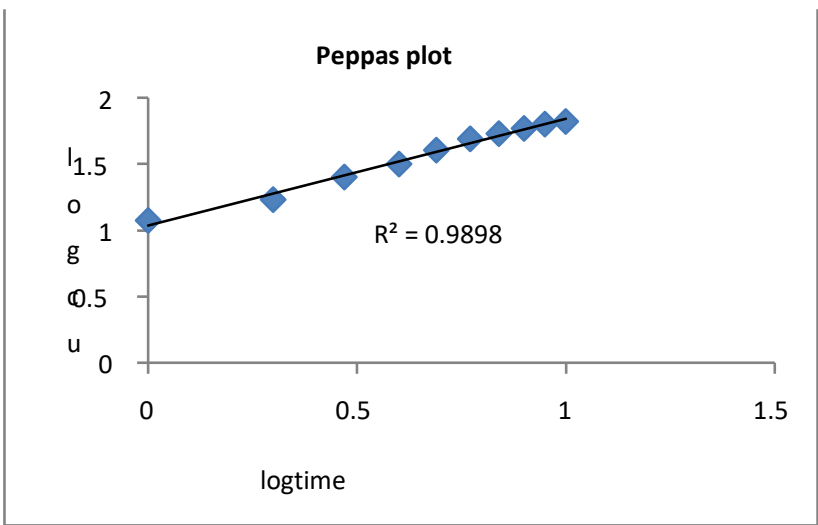

Figure 5.3: Zero order, First order, Higuchi and Peppas plot for F4 Formulation.

\section{CONCLUSION}

Pioglitazone has good solubility in acidic $\mathrm{pH}$. It has good absorption from acidic environment. By preparing floating tablets of Pioglitazone, its bioavailability can be enhanced as more amount of drug will be absorbed from stomach. Pioglitazone is having high melting point of $183-184^{\circ} \mathrm{C}$ which is best suitable for thermal sintering technique. When the tablets were exposed to higher temperature like 50, 60, 70ㅇ $\mathrm{C}$ and for 1, 2, $3 \mathrm{hrs}$ the polymer will melt and entrap the drug by forming matrix.

The formation of matrix in sintering depends on both on temperature and time of exposure of tablets. If both are increased the stronger matrices will be formed promoting prolong drug release.

As the gastric emptying also plays a major role in the release of drug from dosage form. The optimized formulation $\mathrm{F} 3(\mathrm{SA}+\mathrm{CW}+\mathrm{XG}), \mathrm{F} 4(\mathrm{EVA}+\mathrm{CW}+\mathrm{SA})$ sintered at $70 \circ \mathrm{C}$ for $3 \mathrm{hr}$, showed drug release for $12 \mathrm{hrs}$ and also showed sustaining action.

Hardness of the formulation F3, F4 increased with increase in sintering temperature and duration of exposure, whereas the friability decreases with increasing in sintering temperature and time of exposure.

Swelling was not much seen in the formulation as it forms a mesh like structure upon sintering which indicates a matrix formation. The floating behavior of tablets showed acceptable floating lag time of less than $10 \mathrm{~min}$ and total floating time of more than $24 \mathrm{hrs}$. Further increase in sintering temperature and time of exposure made the tablet light weight that permits the faster floating behavior.

As per the literature review though the floating tablets of Pioglitazone were prepared they couldn't show the sustain action for long period. Thermal sintering is a novel technique which is employed for the preparation of gastro retentive drug delivery of Pioglitazone which is not reported earlier. The present formulation F3 $(\mathrm{SA}+\mathrm{CW}+\mathrm{XG}), \mathrm{F} 4$ (EVA+CW+SA) showed good sustaining action up to $>12 \mathrm{hrs}$ promoting prolonged release of drug in the acidic environment that will be helpful to improve bioavailability of drug.

Hence the present work shows the applicability of EVA and waxes in thermal sintering and preparation of gastro retentive drug delivery.

Finally it can be concluded that the aim of current research work Formulation and Evaluation of Sintered Gastroretentive Tablets of Pioglitazone successfully achieved. 


\section{REFERENCES}

1. Leon lachman, Herbert A. Lieberman, Theory and practice of Industrial pharmacy. Tablets; fourth edition , 2017; 449$473,481$.

2. Satinderkakar, Ramandeep singh and ShallusandhanGastroretentive drug delivery system : A review; 29 march 2015; vol.9(12): pp.405-417.

3. Amit kumar Nayak, Ruma maji- Gastroretentive Drug Delivery System: a review, vol.3 issue 1, January- march 2010.

4. Rouge N, Alleman E, Gex-Fabry M, Balant L, Cole ET, Buri $P$, Doelker E. Comparative pharmacokinetic study of a floating multiple unit capsule, a high density multiple -unit capsule and an immediate -release tablet containing 25mg atenolol. Pharm Acta Helbetiae 1998; 73: 81-7.

5. Streubel A, Siepmann J, Bodmeier R. Multiple unit Gastroretentive drug delivery : a new preparation method for low density microparticles. J Microencapsul 2003; 20: 329-47.

6. Santus G, Lazzarini G, Bottoni G, Sandefer EP, Page RC, Doll WJ, Ryo UY, Digenis GA. An invitro-invivo investigation of oral bioadhesive controlled release furosemide formulations. Eur J Pharm Biopharm 1997; 44: 39-52.

7. Klausner EA, Lavy E, Friedman M, Hoffman A. Expandable gastroretentive dosage forms. J control release 2003; 90 : 143-62.

8. Deshpande AA, Shah N, Rhodes CT, Malik W. Development of a novel controlled release system for gastric retention. Pharm Res 1997; 14: 815-19.

9. Chandan mohanty, Sintering technique in pharmaceutical sciencs: a brsief review; International Journal of pharmacy and technology; march -2011, vol.3, issue no.1, 799806.

10. Chandan mohanty, KV Subrahmanyam, Pasupuleti Chandana, Anthati swathi; Apllicability of sintering technique in fabrication of controlled release dosage forms; international journak of innovative pharmaceutical sciences and research: 2018; 6(5): 2347-2154.

11. Bhanja satyabrata, Ellaih $P$, Mohanty Chandan, KVR Murthy, P Bibhutibhusan, Padhysudhirkuam; Design and invitro evaluation of mucoadhesive buccal tablets of perindopril prepared by sintering technique; international journal of pharmactech research; july-sept 2010; vol.2; no.3: $1810-1823$.

Source of Support: The author(s) received no financial support for the research, authorship, and/or publication of this article.

Conflict of Interest: The author(s) declared no potential conflicts of interest with respect to the research, authorship, and/or publication of this article.

For any question relates to this article, please reach us at: editor@globalresearchonline.net New manuscripts for publication can be submitted at: submit@globalresearchonline.net and submit_ijpsrr@rediffmail.com 